\title{
Simulation Method of Main Cable Temperature for Suspension Bridge
}

\author{
Ying Wang ${ }^{1, a}$, Muyu Liu, b \\ ${ }^{1}$ Hubei Key Laboratory of Roadway Bridge\& Structure Engineering, Wuhan University of \\ Technology , Wuhan 430070 ,P, R, China \\ awyisbest@163.com, ${ }^{b}$ liumuyu@whut.edu.cn
}

Keywords:Thermal parameters, Heating curves, Main cable, Temperature field, Parameter fitting. Abstract. Solid thermal finite element model of suspension bridge main cable was established by finite element software ANSYS. Layered grid was divided along the radial direction of main cable. Main cable thermal parameters ,including heat conductivity coefficient, specific heat, thermal expansion coefficient were fitting with least square method. Three-dimensional transient temperature field of main cable was simulatd based on the thermal parameter fitting results. Main girder and tower of the suspension were made up of beam element. Solid thermal model of main cable was connected with suspension bridge for that degree of freedom of main cable was consistent with that of main girder and tower. This model can accurately simulate the uneven temperature field of main cable under fire scenario and calculate elastic modulus, tensile strength under high temperature.

\section{Introduction}

Suspension bridges were important traffic channels of city and shared the huge traffic flows. At the same time, main cables which were important component of suspension bridges, were subjected to large tensile stress. Once tanker burning occurred, temperature of main cables would rise rapidly and then ultimate bearing capacity and the elasticity modulus of main cables would drop significantly. The high temperature had a great influence on mechanical properties of main cable.

At present, some scholars have done thermal analysis for cable system.carried out the structure of the cable temperature field simulation simulation. Lijun Li made a simulation on the cables under high temperature and heat flux density of main and suspender cables of suspension bridge change with fire situation was observed through the numerical simulation[1]. The transient space temperature field of bearing elements was established. But, the research used beam elements to simulation the main cable for that the suspension bridge was too huge. As a result, temperature of man cable cross section was the same and this may caused some error in the research. Bo Ning has researched on the temperature field of the cable with protection layer using ANSYS[2]. The inner temperature field of steel cables under the fire disaster of big tank trucks was gained and the ultimate bearing capacity and fire resistance time of steel cables under fire were calculated. In the research, thermal parameters (specific heat, heat conductivity coefficient, thermal expansion coefficient) were selected according to the reference. So, thermal parameters were straggling and the result was inaccurate. Muyu Liu has researched on numerical simulation of ultimate of slings for three-tower and four-span suspension bridge under tanker fire.The calculation compared temperature field of $\mathrm{HC}_{\mathrm{inc}}$ curve with that of ISO834 curve and risk prevention measures for three-tower and four-span suspension bridge under vehicle fire were put foward[3,4].

This research simulated transient temperature field of suspension main cable under fire scenario by ANSYS. Solid thermal model of main cable was connected with suspension bridge for that degree of freedom of main cable was consistent with that of main girder and tower which were made up of beam element. Thermal parameters of main cable were fitting according to the least square method to make the thermal parameters of the minimum error. Temperature field of main cables was obtained through thermal analysis according to the solid thermal finite element model of suspension bridge main cable and elasticity modulus, tensile strength were calculated under high temperature to provide a reference for bridge fire resistance. 


\section{Temperature field calculation theory and temperature field of main cable simulation}

Transient heat conduction equation. Three-dimensional heat conduction equation is shown in Eq.1.

$c \rho \frac{\partial u}{\partial t}=\frac{\partial}{\partial \mathrm{x}}\left(k \frac{\partial u}{\partial \mathrm{x}}\right)+\frac{\partial}{\partial y}\left(k \frac{\partial u}{\partial y}\right)+\frac{\partial}{\partial z}\left(k \frac{\partial u}{\partial z}\right)$

Where, $u$-temperature at position $(\mathrm{x}, \mathrm{y}, \mathrm{z})$ and time $\mathrm{t} ; t$-duration fire; $\rho$-density; $\mathrm{c}$ - specific heat; $\mathrm{x}, \mathrm{y}, \mathrm{z}$ - three-dimensional coordinates; $\mathrm{k}$ - thermal conductivity.

Thermal analysis modeling method of main cable. Because most of the diameter size of the suspension bridge main cable between $0.5 \mathrm{~m}$ to $1.0 \mathrm{~m}$, Temperature has a uneven distribution along the diameter direction of main cable for that diameters of main cables varied from $0.5 \mathrm{~m}$ to $1.0 \mathrm{~m}$. If the research used beam elements to simulation the main cable for that the suspension bridge was too huge, temperature of man cable cross section was the same and this may caused some error in the research. If the whole bridge was made up of solid elements, the number of elements was too much. So in this research, main cables were made up of solid elements(Solid70) and layered grid was divided along the radial direction of main cables to simulate uneven temperature field of main cables, as shown in Fig.1. Solid70 element has heat transfer capability on the three directions and can be used for transient thermal analysis.

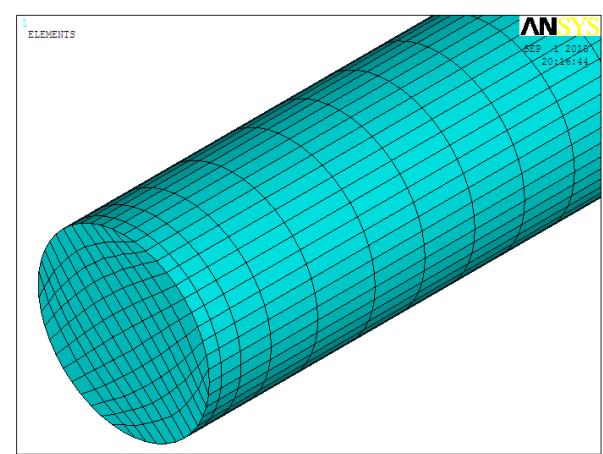

Fig.1 Solid thermal model of main cable

Tower and main girder were made up of beam elements. Solid thermal model of main cable was connected with suspension bridge for that degree of freedom of main cable was consistent with that of main girder and tower. In this method, The model reduced large number of elements. At the same time, uneven temperature field of main cable can be obtained under fire scenario and main cable model can connect with the whole suspension bridge to calculate the mechanical properties under high temperature.

\section{Thermal parameters fitting with the least square method}

Thermal parameters of main cable. (1)Heat conductivity coefficient. Heat conductivity coefficient was the quantity of heat through material per unit area and unit time under the condition of the stability heat transfer. The unit was $W /\left(m \cdot{ }^{\circ} \mathrm{C}\right)$ or $W /(m \cdot K)$. Heat conductivity coefficient depended on the composition of the object. (2)Specific heat. Specific heat was the quantity of heat which the object absorbed when it rose $1{ }^{\circ} \mathrm{C}$ per unit mass. It was the ability to store heat. The unit was $J /\left(\mathrm{kg} \cdot{ }^{\circ} \mathrm{C}\right)$ or $J /(\mathrm{kg} \cdot K)$. (3) Thermal expansion coefficient. Thermal expansion coefficient was the elongation when the object rose $1{ }^{\circ} \mathrm{C}$ per unit length. The unit was $m /\left(\mathrm{m} \cdot{ }^{\circ} \mathrm{C}\right)$.

Fitting method. When measured values were discrete, The least square method approximate function could be established for that quadratic sum of the deviation made by the experimental results and calculation results of approximate function was the minimum.

Heat conductivity coefficient of main cable from references [5] to [8] was shown in Fig.2. The value of heat conductivity coefficient was too discrete. So the research took the average of heat conductivity coefficient from references and then the average was fitting by the least square method. 
The average of heat conductivity coefficient was shown in Fig.3 and it was fitting with linear equation by the least square method. Based on the calculation principle of least square method, heat conductivity coefficient fitting equation was shown in Eq.2:

$y=54.107-0.0346 x$

Where, $y$ - heat conductivity coefficien; $\mathrm{x}$ - temperature.

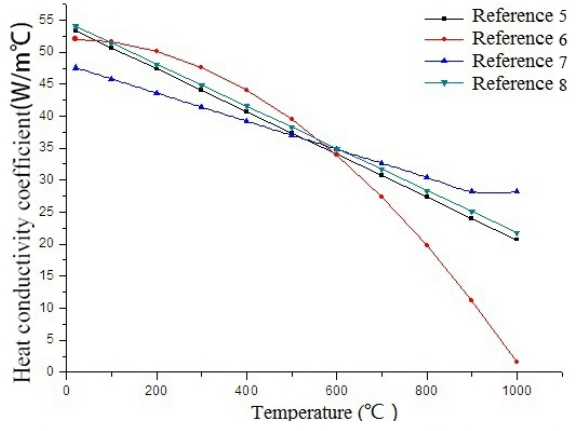

Fig.2 Heat conductivity coefficient of main cable from reference

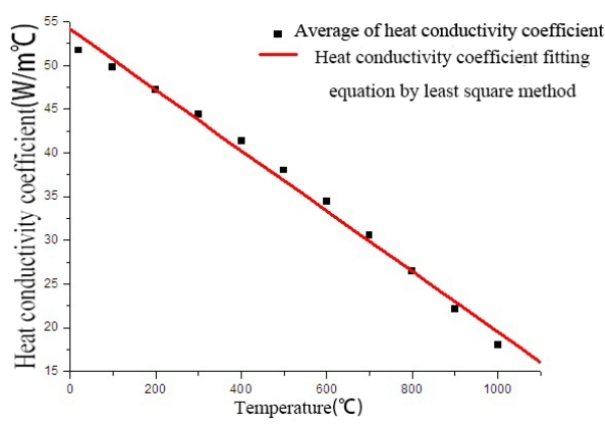

Fig.3 Heat conductivity coefficient fitting by least square method

The average of specific heat and thermal expansion coefficient from references was calculated to obtain the fitting values by the least square method in the same way, as shown in Fig.4 and Fig.5. Specific heat of main cable fitting equation was shown in Eq.3:

$y=444.93+0.4955 x$

Where, $\mathrm{y}$-specific heat; $\mathrm{x}$ - temperature.

And thermal expansion coefficien of main cable fitting equation was shown in Eq.4:

$y=1.135 \times 10^{-5}+7.5 \times 10^{-9} x$

Where, $\mathrm{y}$ - thermal expansion coefficien; $\mathrm{x}$ - temperature.

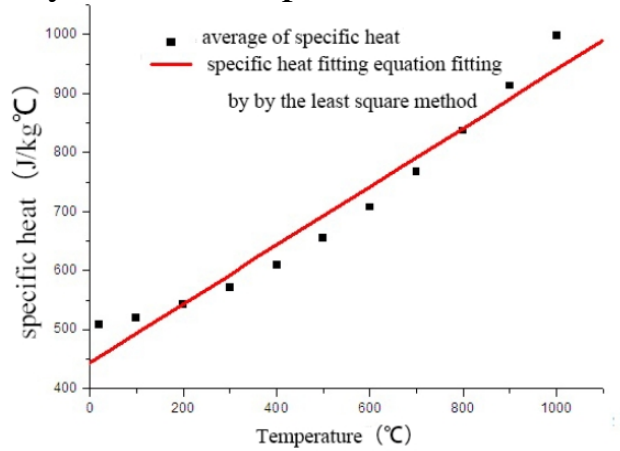

Fig.4 Specific heat fitting by least square method

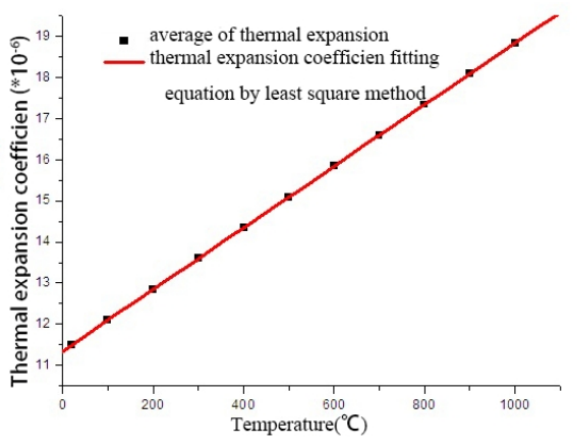

Fig.5 Thermal expansion coefficient fitting by least square method

\section{Numerical simulation of temperature field of Suspension bridge main cable}

Calculation example. Yingwuzhou Yangtze river bridge is located in the center of Wuhan city. The bridge sites $2 \mathrm{~km}$ away from Wuhan Yangtze River bridge. The north side of it is Maying Road in Hanyang, and the south of it is Fuxing Road in Wuchang. It is the world's largest three-tower and four-span composite suspension bridge with the span of $200 m+850 m+850 m+200 m$. The vertical view of the bridge is shown in Fig.6.

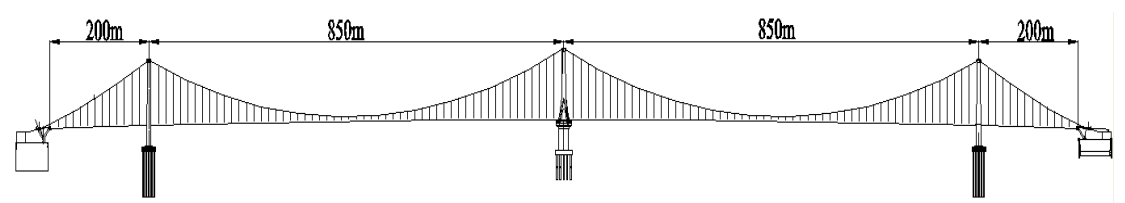

Fig.6 General layout of Yingwuzhou Yangtze river bridge

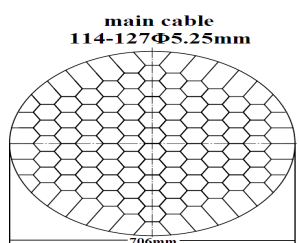

Fig.7 Cross section of main cables

Main cables are made up of high strength galvanized steel wires with $5.1 \mathrm{~mm}$ diameter. The diameter of main cables is $706 \mathrm{~mm}$. Tensile strength of the steel wire was 1770Mpa, as shown in Fig.7. 
Heating curve. For bridge structures, Source of fire is mainly composed of vehicles, especially tankers that carry a lot of fuel oil. Heating curve of tanker is different from that of building structure(i.e. ISO834 heating curve). Energy of fire hazard caused by tanker combustion is more powerful. Temperature of source area can exceed $1000^{\circ} \mathrm{C}$ in 15 minutes. Therefore, this research adopts $\mathrm{HC}_{\text {inc }}$ heating curve provided by France as heating curve of tanker to impose heating load on the bridge, as shown in Fig.8. $\mathrm{HC}_{\mathrm{inc}}$ heating curve is used to describe petroleum fire, such as gasoline, petrol and chemicals. The expression is shown in Eq.5.

$$
T=13\left[20+1080\left(1-0.325 e^{-0.167 t}-0.675 e^{-2.5 t}\right] / 11\right.
$$

Where, $\mathrm{t}$ - $\operatorname{time}(\min ) ; \mathrm{T}$ - temperature at time $\mathrm{t}\left({ }^{\circ} \mathrm{C}\right)$.

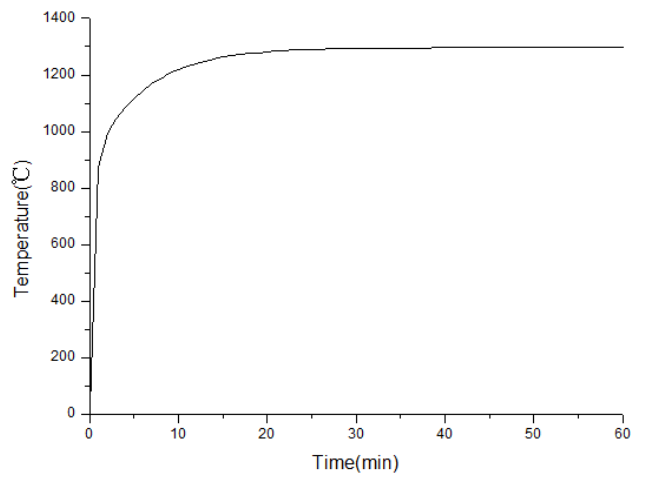

Fig.8 Heating curves of tankers $\left(\mathrm{HC}_{\text {inc }}\right)$

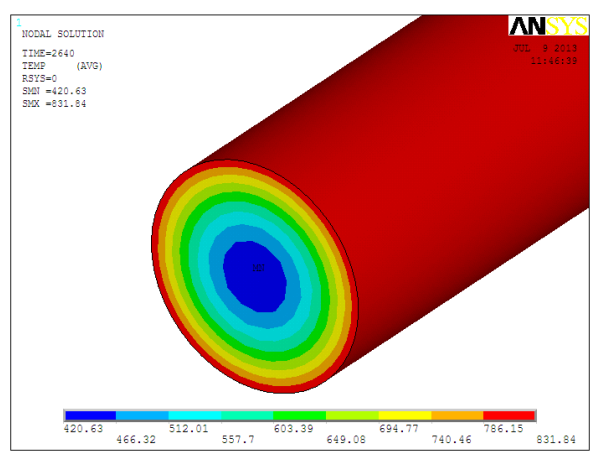

Fig.9 Temperature field of main cable at 44 minutes

Thermal analysis results. Solid thermal finite element model of suspension bridge main cable was established by ANSYS. Layered grid was divided along the radial direction of main cable, as shown in Fig.1. The model had 12368 nodes and 10654 elements. Convection coefficient is $25 \mathrm{~W} /\left(\mathrm{m} \cdot{ }^{\circ} \mathrm{C}\right)$, radiation coefficient is 0.7 . Heating load was imposed on the main cable with $\mathrm{HC}_{\mathrm{inc}}$. Heating load lasted until the main cable was damaged. Thermal analysis was carried out on the main cable. Temperature field figure of the main cable at 44minutes was shown in Fig.9.

Temperature of steel wire inside the main cable rose slowly and reached $421^{\circ} \mathrm{C}$ at 44 minutes. Temperature of steel wire outside the main cable rose rapidly and reached $832^{\circ} \mathrm{C}$ at 44 minutes, as shown in Fig.10.

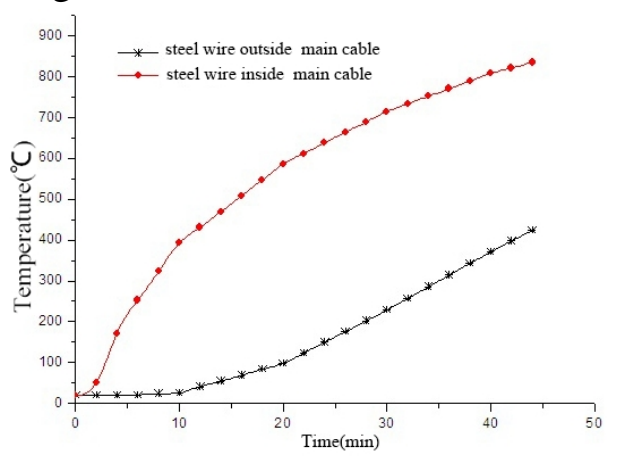

Fig.10 Curves of main cable temperature changed with time

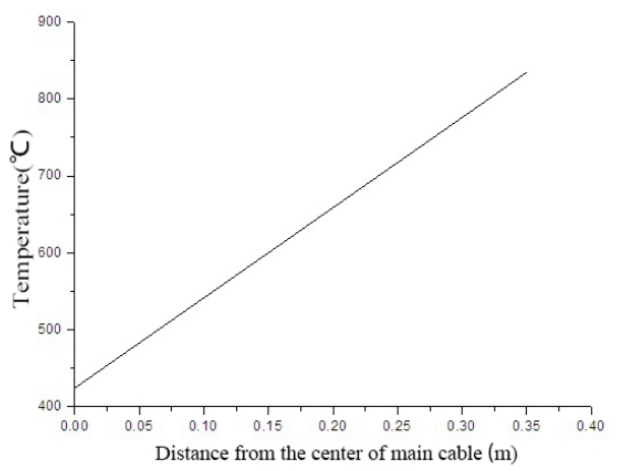

Fig.11 Temperature of main cable cross section along the radius direction

Temperature between wire inside the main cable and steel wire outside the main cable was in linear variation along radius direction. The outside wire temperature rose rapidly during the whole stage. The inside wire temperature rose gently ten minutes before and rose rapidly after 10 minutes. Temperature of main cable cross section was shown in Fig.11.

At 44 minutes, elastic modulus of steel wire outside the main cable dropped rapidly and reached $0.04 E_{S}$ and elastic modulus of steel wire inside the main cable reached $0.57 E_{S}(\mathrm{E}(\mathrm{T})$ was elastic modulus at temperature $\mathrm{T}^{\circ} \mathrm{C}$ and $\mathrm{E}$ was elastic modulus at normal temperature). Tensile strength of steel wire outside the main cable dropped rapidly and reached $0.02 f_{S}$ and tensile strength of steel wire 
inside the main cable reached $0.41 f_{S}\left(\mathrm{f}(\mathrm{T})\right.$ was tensile strength at temperature $\mathrm{T}^{\circ} \mathrm{C}$ and $\mathrm{f}$ was tensile strength at normal temperature), as shown in Fig.12 and Fig.13.
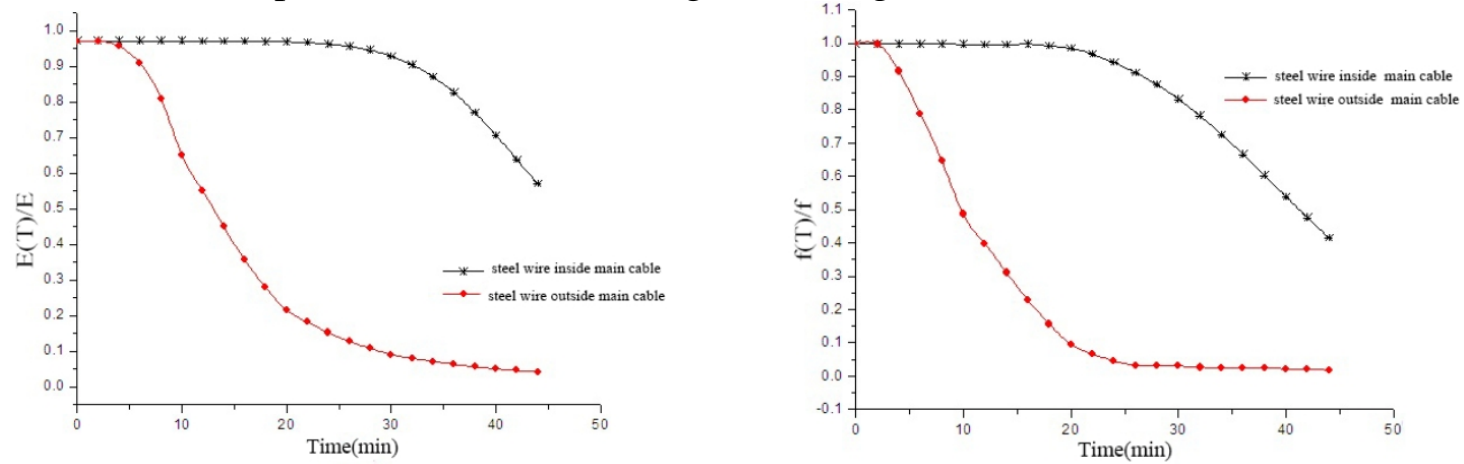

Fig.12 Elasticity modulus of main cable changed with time Fig.13 Tensile strength of main cable changed with time

The result shows that temperature of man cable cross section was uneven. Temperature at the edge of main cable and in the center of main cable had a great difference. So elastic modulus and tensile strength outside the main cable differed much from elastic modulus and tensile inside the main cable. When temperature of suspension bridge main cable was simulated, solid element should be used to simulate the uneven temperature along the cross section of main cable. This method could provide the reference for bridge fire resistance.

\section{Conclusions}

(1)Solid thermal finite element model of suspension bridge main cable was established by ANSYS. Main cable thermal parameters were fitting with least square method. This model can accurately simulate the uneven temperature field of main cable under fire scenario.

(2)Solid thermal model of main cable was connected with suspension bridge for that degree of freedom of main cable was consistent with that of main girder and tower which were made up of beam element. Elastic modulus, tensile strength under high temperature were calculated to provide the reference for bridge fire resistance .

\section{Acknowledgments}

This paper was financially supported by the National Natural Science Fund, "Stability of High Web in Long-span Steel-concrete Composite Bridge Based on the Elastic Rotational Restraint Boundary" (No.51378405), and the Natural Science Fund of Hubei province(No.2013CFA049).

\section{References}

[1]Lijun Li, Xiangbin Wan, Xiaoming Dong: Journal of Heeei University of Technology Vol.38 (2015) pp.659-663. (In Chinese)

[2]Bo Ning, Yongjun Liu: Steel Construction Vol.27 (2012) pp.68-72. (In Chinese)

[3]Muyu Liu, Wei Tian, Ying Wang: Applied Mechanics and Materials Vol.361-363(2013) pp.1187-1193.

[4]Muyu Liu, Wei Tian, Ying Wang: Advanced Materials Research Vol. 919-921(2014) pp.590-597. [5]Nuno Lopes, PauloVilaReal: Fire Safety Journal Vol.50 (2012) pp.35-42.

[6]Lie T T: Journal of Structure Engineering Vol.120 (1993) pp.75-80.

[7]Lie T T. Celikkol B: Material Journal Vol.88 (1991) pp.84-89.

[8]Haoyu Zhang, Wenzhong Zheng: Journal of Harbin Institute of Technology Vol.39 (2007) pp.861-865. (In Chinese)

[9]Maria Garlock, Ignacio Paya-Zaforteza, Venkatesh Kodur, Li Gu: Engineering Structures Vol.35 (2012) pp.89-96. 
[10]Ian Bennetts and Khalid Moinuddin : Journal of Fire Protection Engineering Vol.19 (2009) pp.85-92.

[11]I. Payá-Zaforteza, M.E.M. Garlock: Journal of Constructional Steel Research Vol.75 (2012) pp.93-99.

[12]Venkatesh Kodur, Esam Aziz and Mahmud Dwaikat: submitted to Journal of Bridge Engineering. 2012.

[13]Yinqing Li, Daozhen Ma, Jian Xu: Fire Protection Design Calculation and Construction of Building Structure(Construction Industry Publications, Beijing, China 1991).(In Chinese)

[14]Lingli Shi, Benniu Zhang: Journal of Chongqing Jiaotong University Vol.30 (2011) pp.1290-1296. (In Chinese)

[15]Xudong Shi, Zhenhai Guo: Journal of civil engineering Vol.33 (2000) pp.36-42. (In Chinese) 